\title{
Training types associated with knowledge and experience in public health workers
}

\author{
Zui Narita ${ }^{1^{*}}$ D, Yoshio Yamanouchi ${ }^{2}$, Kazuo Mishima ${ }^{3,4}$, Yoko Kamio $^{5,6}$, Naoko Ayabe ${ }^{7}$, Ryoko Kakei ${ }^{8}$ and \\ Yoshiharu Kim ${ }^{1}$
}

\begin{abstract}
Background: Training non-specialist workers in mental healthcare improves knowledge, attitude, confidence, and recognition of mental illnesses. However, still little information is available on which type of mental health training is important in the improvement of these capacities.
\end{abstract}

Methods: We studied web-based survey data of 495 public health workers to examine training types associated with knowledge and experience in supporting individuals with mental illness. Multivariable logistic regression analysis was conducted to evaluate the association between a lack of knowledge and experience (outcome) and mental health training (exposure). We fitted three regression models. Model 1 evaluated unadjusted associations. Model 2 adjusted for age and sex. Model 3 adjusted for age, sex, years of experience, mental health full-time worker status, and community population. Bias-corrected and accelerated bootstrap confidence intervals (Cls) were used.

Results: For all training types, the association between a lack of knowledge and experience and mental health training attenuated as the model developed. In Model 3, a lack of knowledge and experience was significantly associated with training in specific illness $(\mathrm{OR}, 0.54 ; 95 \% \mathrm{Cl}, 0.32-0.93)$ and screening and assessment (OR, 0.63; 95\% $\mathrm{Cl}, 0.39-0.99)$. Non-significant results were produced for training in counseling, psychosocial support, collaborative work, and law and regulation in Model 3.

Conclusions: We believe that the present study provides meaningful information that training in specific illness and screening and assessment may lead to knowledge and experience of public health workers. Further studies should employ a longitudinal design and validated measurements.

Keywords: Training course, Community mental health, Public health, Primary care

\section{Background}

The coronavirus disease 2019 (COVID-19) global pandemic highlights the importance of mental illness as one of the significant causes of disability and the global burden of disease [1-4]. Mental illness has the longest years lived with disability and is the same level as cardiovascular and circulatory diseases in disability-adjusted lifeyears [5]. Across all regions of the world, mental illness

\footnotetext{
* Correspondence: zuinarita@ncnp.go.jp

'Department of Behavioral Medicine, National Institute of Mental Health, National Center of Neurology and Psychiatry, 4-1-1 Ogawahigashi, Kodaira, Tokyo 187-8553, Japan

Full list of author information is available at the end of the article
}

is highly prevalent and affecting individuals [6]. Approximately one-fifth of individuals in a general population experiences 12-month mental illness [6]. Previous data suggested that the global direct and indirect economic costs of mental illness were estimated at US $\$ 2.5$ trillion [7]. Thus, adequate management of mental illness is crucial for social recovery in the post-COVID-19 era.

These decades have seen significant changes of mental health care in many countries worldwide [8]. Of these, the development of community-based care was one of the essential changes $[8,9]$. In communities, nonspecialist workers, such as primary care and public 
health workers, need to manage individuals with mental illness. Integrating mental health services at the primary care level is the most viable way to decrease the treatment gap and ensure that people undergo the mental health care they need [10].

Certain skills and competencies are required to assess, diagnose, treat, support, and refer individuals with mental illness. Therefore, non-specialist workers need to be adequately prepared and supported in their mental health work $[10,11]$. The World Health Organization (WHO) Mental Health Action Plan (2013-2020) and the WHO Mental Health Gap Action Programme (mhGAP) recommended adequate training in non-specialist workers in diagnosing and treating mental illness [12, 13]. This is specifically of relevance in communities with small or previously non-existent budgets for mental health [14].

Previous studies with a pre-post design showed significant effects of mental health training on non-specialist workers' knowledge, attitude, confidence, and recognition of mental illnesses [15-19]. Moreover, a clusterrandomized controlled trial showed that training of nonspecialist workers improved the detection of mental illnesses [20]. These effects of mental health training were also verified by a systematic review including 29 studies [14]. Nevertheless, still little information is available on which type of mental health training is important in the improvement of such capacities. Japan reportedly has a poor quality of community mental health [21, 22], and such information is crucial to improve the mental health service. In the present study, we studied web-based survey data of 495 public health workers in Japan to examine training types associated with knowledge and experience in supporting individuals with mental illness.

\section{Methods \\ Sample}

We analyzed data from public health workers working at community health care centers in Japan who underwent a cross-sectional web-based survey. The survey was administered from 8 January to 28 February 2018 using SurveyMonkey software. Participants were recruited by the National Center of Neurology and Psychiatry. We mailed letters to managers of all 589 health care centers in Japan. Next, each manager distributed the letters to public health workers in the health care center. The letter showed the URL of the survey so that each participant could access it. Note that we only included certified individuals such as public health nurses or social workers. A total of 643 public health workers agreed to participate. Of these, 495 public health workers (77.0\%) completed the survey. Details of participants' professional backgrounds are shown in Supplementary Table S1. The survey was approved by the National Center of
Neurology and Psychiatry Institutional Review Board (A2018-097). All participants provided written informed consent.

\section{Lack of knowledge and experience}

Participants self-reported if they had a lack of knowledge and experience enough to support individuals with mental illness. They were asked to select one of seven response options regarding how much percentage of cases they had a lack of knowledge and experience: (1) 100$80 \%$, (2) $79-60 \%$, (3) $59-40 \%$, (4) $39-20 \%$, (5) seldom, (6) not at all, or (7) not sure. Endorsing (1), (2), or (3) was regarded as a lack of knowledge and experience.

\section{Mental health training}

Participants self-reported which type of mental health training they underwent. They were asked to select all that apply from six response options: (1) specific illness, (2) screening and assessment, (3) counseling, (4) psychosocial support, (5) collaborative work, or (6) law and regulation. We included the components featured in the mhGAP Intervention Guide [23]. For instance, the mhGAP Intervention Guide recommends contacting legal resources in a situation of maltreatment, abuse, and neglect [23].

\section{Sociodemographic factors}

Sociodemographic factors that may confound the relationship between each training and knowledge and experience were included in analyses as covariates. Participants self-reported sociodemographic factors, including age (29 years or younger, 30-39 years, 40-49 years, 50 years or older), sex, years of experience, mental health full-time worker status (yes/no), community population $(50,000$ or smaller, $50,000-200,000,200,000$ $500,000,500,000-1000,000,1000,000$ or larger). Years of experience and mental-health full-time worker status were adjusted for since they may be linked to a higher chance of having training and more knowledge and experience. Community population was included because the relationship to community individuals may be associated with training's success [24]. Years of education were not adjusted for as all participants had at least a college degree.

\section{Statistical analysis}

All statistical analyses were conducted by using $R$ version 4.1.0. Baseline characteristics of participants who lacked knowledge and experience and those who did not were compared using independent-sample t-tests and chi-square tests. Multivariable logistic regression analysis was conducted to evaluate the association between a lack of knowledge and experience (outcome) and mental health training (exposure). We fitted three regression 
models. Model 1 evaluated unadjusted associations. Model 2 adjusted for age and sex. Model 3 adjusted for age, sex, years of experience, mental health full-time worker status, and community population. Biascorrected and accelerated bootstrap confidence intervals (CIs) were used to acquire an accurate estimation [2527]. In conducting bootstrap CIs, the size of the bootstrap sample was set at 1000 with $95 \%$ CIs [28]. The significance level was set at a $p$-value less than 0.05 .

\section{Results}

\section{Baseline characteristics}

Table 1 shows the baseline characteristics of participants. A total of 308 participants (62.2\%) reported a lack of knowledge and experience. Individuals with a lack of knowledge and experience showed fewer years of experience $(p<0.001)$, lower proportion of mental health full- time workers $(p=0.001)$, training in specific illness $(p<0.001)$, screening and assessment $(p=0.005)$, psychosocial support $(p=0.03)$, and law and regulation $(p=$ $0.001)$. Two groups significantly differed in age $(p<0.001)$, i.e., individuals with a lack of knowledge and experience were more likely to be 39 years or younger and less likely to be 40 years or older. No significant difference was shown in sex, community population, and training in counseling and collaborative work. Training in specific illness was most frequently reported in both groups (68.8 and $82.3 \%$, respectively). Details of training in specific illness are shown in Supplementary Table S2.

\section{Relationship between knowledge and experience and training types}

Table 2 summarizes the results of multivariable logistic regression analyses. For all training types, the association

Table 1 Baseline characteristics of study participants

\begin{tabular}{|c|c|c|c|c|}
\hline \multirow[t]{2}{*}{ Characteristic } & \multirow{2}{*}{$\begin{array}{l}\text { Overall } \\
(n=495)\end{array}$} & \multicolumn{2}{|c|}{ Lack of knowledge and experience } & \multirow[t]{2}{*}{$P$ value } \\
\hline & & Yes $(n=308)$ & No $(n=187)$ & \\
\hline$\overline{\text { Sex, No. }(\%)^{a}}$ & & & & 0.08 \\
\hline Male & 87 (17.6) & $47(15.4)$ & $40(21.5)$ & \\
\hline Female & $405(81.8)$ & $259(84.6)$ & $146(78.5)$ & \\
\hline Age, No. $(\%)^{b}$ & & & & $<0.001$ \\
\hline-29 & $91(18.4)$ & $77(25.0)$ & $14(7.5)$ & \\
\hline 30-39 & $148(29.9)$ & $99(32.1)$ & $49(26.3)$ & \\
\hline $40-49$ & $138(27.9)$ & $78(25.3)$ & $60(32.3)$ & \\
\hline $50-$ & $117(23.6)$ & $54(17.5)$ & $63(33.9)$ & \\
\hline Years of experience, mean (SD), y & $15.7(10.3)$ & $13.2(9.6)$ & $19.5(10.3)$ & $<0.001$ \\
\hline Mental health full-time worker, No. $(\%)^{c}$ & & & & $=0.001$ \\
\hline No & $297(60.0)$ & $202(66.2)$ & $95(51.4)$ & \\
\hline Yes & $193(38.9)$ & $103(33.8)$ & $90(48.6)$ & \\
\hline \multicolumn{5}{|l|}{ Community population, No. (\%) } \\
\hline$-50,000$ & $176(35.6)$ & $120(39.0)$ & $56(30.1)$ & 0.09 \\
\hline $50,000-200,000$ & $168(33.9)$ & $106(34.4)$ & $62(33.3)$ & \\
\hline $200,000-500,000$ & $75(15.2)$ & $42(13.6)$ & $33(17.7)$ & \\
\hline $500,000-1000,000$ & $38(7.7)$ & $17(5.5)$ & $21(11.3)$ & \\
\hline $1000,000-$ & $36(7.2)$ & $22(7.1)$ & $14(7.5)$ & \\
\hline \multicolumn{5}{|l|}{ Training type, No. (\%) } \\
\hline Specific illness & $365(73.7)$ & $212(68.8)$ & $153(82.3)$ & $<0.001$ \\
\hline Screening and assessment & $127(25.7)$ & $72(23.4)$ & $55(34.9)$ & 0.005 \\
\hline Counseling & $317(64.0)$ & $191(62.0)$ & $126(67.7)$ & 0.20 \\
\hline Psychosocial support & $173(34.9)$ & $97(31.5)$ & $76(40.9)$ & 0.03 \\
\hline Collaborative work & $226(45.7)$ & $135(43.8)$ & $91(48.9)$ & 0.27 \\
\hline Law and regulation & $171(34.5)$ & $90(29.2)$ & $81(43.5)$ & 0.001 \\
\hline
\end{tabular}

a Missing data for three participants

b Missing data for one participant

c Missing data for five participants

d Missing data for two participants 
Table 2 Associations between a lack of knowledge and experience and mental health training

\begin{tabular}{|c|c|c|c|c|c|}
\hline & $\begin{array}{l}\text { Lack of knowledge and experience } \\
\text { Odds ratio } \\
\text { [95\% confidence interval] }\end{array}$ & & & & \\
\hline \multicolumn{6}{|l|}{ Model 1, unadjusted } \\
\hline \multicolumn{6}{|l|}{ Training type } \\
\hline Specific illness & $0.48^{* *}[0.30-0.75]$ & & & & \\
\hline Screening and assessment & $0.57^{* *}[0.37-0.86]$ & & & & \\
\hline Counseling & & $0.78[0.53-1.15]$ & & & \\
\hline Psychosocial support & & & $0.67^{*}[0.45-0.98]$ & & \\
\hline Collaborative work & & & & $0.81[0.56-1.19]$ & \\
\hline Law and regulation & & & & & $0.54^{* *}[0.37-0.79]$ \\
\hline \multicolumn{6}{|l|}{ Model 2, adjusted for age and sex } \\
\hline \multicolumn{6}{|l|}{ Training type } \\
\hline Specific illness & $0.51^{* *}[0.31-0.84]$ & & & & \\
\hline Screening and assessment & $0.63^{*}[0.41-0.96]$ & & & & \\
\hline Counseling & & $0.83[0.56-1.25]$ & & & \\
\hline Psychosocial support & & & $0.67[0.45-1.01]$ & & \\
\hline Collaborative work & & & & $0.94[0.64-1.38]$ & \\
\hline Law and regulation & & & & & $0.63^{*}[0.42-0.93]$ \\
\hline \multicolumn{6}{|c|}{ Model 3, adjusted or age, sex, years of experience, full-time worker status, and community population } \\
\hline \multicolumn{6}{|l|}{ Training type } \\
\hline Specific illness & $0.54^{*}[0.32-0.93]$ & & & & \\
\hline Screening and assessment & $0.63^{*}[0.39-0.99]$ & & & & \\
\hline Counseling & & $0.76[0.49-1.19]$ & & & \\
\hline Psychosocial support & & & $0.73[0.47-1.13]$ & & \\
\hline Collaborative work & & & & $0.98[0.65-1.48]$ & \\
\hline Law and regulation & & & & & $0.73[0.47-1.13]$ \\
\hline
\end{tabular}

between a lack of knowledge and experience and mental health training attenuated as the model developed (i.e., odds ratios were lowest in Model 1 and highest in Model 3). In Model 3, a lack of knowledge and experience was significantly associated with training in specific illness (OR, 0.54; 95\% CI, 0.32-0.93) and screening and assessment (OR, 0.63; 95\% CI, 0.39-0.99). Training in psychosocial support and law and regulation showed a statistical significance in Model 1 and Model 2, which disappeared in Model 3. Non-significant results were produced for training in counseling and collaborative work in all Model 1, Model 2, and Model 3.

\section{Discussion}

To our knowledge, this is the first study evaluating the efficacy of specific types of mental health training in public health workers in Japan. Among various types of mental health training, training in specific illness and screening and assessment was significantly associated with the sense of knowledge and experience after the adjustment of various potential confounders. These findings are in line with past reports showing significant effects of mental health training on non-specialist workers' capacities, e.g., knowledge and recognition of mental illnesses [15-20]. The present study may provide information improving the management of mental illness, which is specifically crucial for social recovery in the post-COVID-19 era.

Although our finding is based on the data from a Japanese sample and may not be readily generalizable to other countries, the present study implies that the concept-/assessment-oriented training may enhance public health workers' capacities. Indeed, the mhGAP intervention guide for non-specialist workers recommends conducting an assessment as an essential clinical practice in mental health [23]. Our finding supports this recommendation from the viewpoint of training efficacy. To note, training in specific illness and screening and assessment may improve knowledge directly related to each mental illness, which may lead to the confidence of public health workers. 
Japan has the highest number of psychiatric beds per capita in the world [29], which may co-occur with polypharmacy and long-term hospitalization [30, 31]. Hospital discharge and transition to the communities have been warranted to achieve patient-centered care [32]. To achieve this, the "Reform Vision of Mental Health and Welfare" was released in 2004 [33]. However, Japan still has long-term psychiatric hospitalization (mean, 265.8 days) as of 2019 [34], partly resulting from insufficient community support [22, 35]. The potential approach to improve public health workers' capacities shown in the present study may have clinical implications in enhancing the quality of community mental health in Japan.

\section{Limitations}

Several limitations should be acknowledged here. First, a lack of knowledge and experience was measured in a subjective manner, which may not reflect the actual capacity of public health workers. It may have been vulnerable to recall and social desirability biases. Second, both a lack of knowledge and experience and mental health training were self-reported via a single-item questionnaire. The cut-off for having a lack of knowledge and experience was arbitrary. Future studies should employ validated measurements to address these issues. Third, this study is based on cross-sectional web-based survey data that does not ascertain the temporal order of events or make causal inferences. Studies with longitudinal data are warranted to understand the causal relationship. Fourth, it is unclear if public health workers' subjective knowledge and experience result in an improved outcome for patients with mental illness. Finally, our models aimed to adjust for confounding between training types and knowledge and experience rather than to maximize the overall goodness-of-fit, and thus should not be used for prediction.

\section{Conclusions}

Despite these limitations, we believe that the present study provides meaningful information that training in specific illness and screening and assessment may lead to knowledge and experience of public health workers. Further studies should employ a longitudinal design and validated measurements.

\section{Abbreviations}

COVID-19: Coronavirus disease 2019; WHO: World Health Organization; mhGAP: Mental Health Gap Action Programme

\section{Supplementary Information}

The online version contains supplementary material available at https://doi. org/10.1186/s13690-022-00788-4.

Additional file 1.

\section{Acknowledgments}

We wish to thank Dr. Keiko Shimazu for her assistance in implementing the research.

\section{Authors' contributions}

Initial research questions were devised by YK. Analyses were conducted by $Z N$. The manuscript was written by $Z N$ and finalized by $Y K$ and with substantial text contribution from all authors. All the authors read and approved the final manuscript.

\section{Funding}

The present study was supported by the Health Labour Sciences Research Grant

Availability of data and materials

Not applicable.

\section{Declarations}

Ethics approval and consent to participate

The present study was approved by the National Center of Neurology and Psychiatry Institutional Review Board (A2018-097). Informed, written consent was obtained from each study participant.

Consent for publication

Not applicable.

\section{Competing interests}

The authors declare that they have no competing interests.

\section{Author details}

'Department of Behavioral Medicine, National Institute of Mental Health, National Center of Neurology and Psychiatry, 4-1-1 Ogawahigashi, Kodaira, Tokyo 187-8553, Japan. ${ }^{2}$ Aisei Century Hospital, Nagoya, Aichi, Japan. ${ }^{3}$ Department of Neuropsychiatry, Akita University Graduate School of Medicine, Akita, Japan. ${ }^{4}$ Department of Sleep-Wake Disorders, National Institute of Mental Health, National Center of Neurology and Psychiatry, Tokyo, Japan. ${ }^{5}$ Department of Preventive Intervention for Psychiatric Disorders, National Institute of Mental Health, National Center of Neurology and Psychiatry, Tokyo, Japan. ${ }^{6}$ Institute of Education and Human Development, Ochanomizu University, Tokyo, Japan. ${ }^{7}$ Department of Regional Studies and Humanities, Faculty of Education and Human Studies, Akita University, Akita, Japan. ${ }^{8}$ Wayo Women's University, Chiba, Japan.

Received: 22 June 2021 Accepted: 8 January 2022

Published online: 27 January 2022

\section{References}

1. Murray CIL, Vos T, Lozano R, Naghavi M, Flaxman AD, Michaud C, et al. Disability-adjusted life years (DALYS) for 291 diseases and injuries in 21 regions, 1990-2010: a systematic analysis for the global burden of disease study 2010. Lancet Lond Engl. 2012;380(9859):2197-223. https://doi.org/10.1 016/S0140-6736(12)61689-4.

2. Rehm J, Shield KD. Global burden of disease and the impact of mental and addictive disorders. Curr Psychiatry Rep. 2019;21(2):10. https://doi.org/10.1 007/s11920-019-0997-0.

3. Zhou H, Wang X, Du R, Cheng X, Zheng K, Dong S, et al. The work experience of newly recruited male nurses during COVID-19:a qualitative study. Asian Nurs Res. 2021;15(3):203-9. https://doi.org/10.1016/..anr.2021.05. 001.

4. Taquet M, Geddes JR, Husain M, Luciano S, Harrison PJ. 6-month neurological and psychiatric outcomes in 236379 survivors of COVID-19: a retrospective cohort study using electronic health records. Lancet Psychiatry. 2021;8(5):416-27. https://doi.org/10.1016/S2215-0366(21)00084-5.

5. Vigo D, Thornicroft $G$, Atun R. Estimating the true global burden of mental illness. Lancet Psychiatry. 2016;3(2):171-8. https://doi.org/10.1016/S2215-03 66(15)00505-2.

6. Steel Z, Marnane C, Iranpour C, Chey T, Jackson JW, Patel V, et al. The global prevalence of common mental disorders: a systematic review and metaanalysis 1980-2013. Int J Epidemiol. 2014;43(2):476-93. https://doi.org/10.1 093/ije/dyu038. 
7. Trautmann S, Rehm J, Wittchen $\mathrm{H}$. The economic costs of mental disorders. EMBO Rep. 2016;17(9):1245-9. https://doi.org/10.15252/embr.201642951.

8. World Health Organization. Human resources and training in mental health. Geneva: World Health Organization; 2005.

9. Thornicroft G, Deb T, Henderson C. Community mental health care worldwide: current status and further developments. World Psychiatry Off J World Psychiatr Assoc WPA. 2016;15(3):276-86. https://doi.org/10.1002/ wps.20349.

10. World Health Organization. Integrating mental health into primary care: a global perspective. Geneva: World Health Organization; 2008.

11. Kakuma R, Minas H, van Ginneken N, Dal Poz MR, Desiraju K, Morris JE, et al. Human resources for mental health care: current situation and strategies for action. Lancet Lond Engl. 2011;378(9803):1654-63. https://doi.org/10.1016/ S0140-6736(11)61093-3.

12. World Health Organization. Mental health action plan 2013-2020. Geneva; 2013.

13. World Health Organization. mhGAP : Mental Health Gap Action Programme: scaling up care for mental, neurological and substance use disorders. Geneva; 2008.

14. Caulfield A, Vatansever D, Lambert G, Van Bortel T. WHO guidance on mental health training: a systematic review of the progress for nonspecialist health workers. BMJ Open. 2019;9(1):e024059. https://doi.org/1 0.1136/bmjopen-2018-024059.

15. Ayano G, Assefa D, Haile K, Chaka A, Haile K, Solomon M, et al. Mental health training for primary health care workers and implication for success of integration of mental health into primary care: evaluation of effect on knowledge, attitude and practices (KAP). Int J Ment Health Syst. 2017;11(1): 63. https://doi.org/10.1186/s13033-017-0169-8.

16. Li J, Li J, Huang Y, Thornicroft G. Mental health training program for community mental health staff in Guangzhou. China: effects on knowledge of mental illness and stigma Int J Ment Health Syst. 2014;8(1):49. https://doi. org/10.1186/1752-4458-8-49.

17. Armstrong G, Kermode M, Raja S, Suja S, Chandra P, Jorm AF. A mental health training program for community health workers in India: impact on knowledge and attitudes. Int J Ment Health Syst. 2011;5(1):17. https://doi. org/10.1186/1752-4458-5-17.

18. Morawska A, Fletcher R, Pope S, Heathwood E, Anderson E, McAuliffe C. Evaluation of mental health first aid training in a diverse community setting. Int J Ment Health Nurs. 2013;22(1):85-92. https://doi.org/10.1111/j.1447-034 9.2012.00844.x.

19. Wright J, Common S, Kauye F, Chiwandira C. Integrating community mental health within primary care in southern Malawi: a pilot educational intervention to enhance the role of health surveillance assistants. Int I Soc Psychiatry. 2014;60(2):155-61. https://doi.org/10.1177/0020764012471924.

20. Kauye $F$, Jenkins $R$, Rahman A. Training primary health care workers in mental health and its impact on diagnoses of common mental disorders in primary care of a developing country, Malawi: a cluster-randomized controlled trial. Psychol Med. 2014;44(3):657-66. https://doi.org/10.1017/ S0033291713001141.

21. Kanehara A, Umeda M, Kawakami N. World mental health Japan survey group. Barriers to mental health care in Japan: results from the world mental health Japan survey. Psychiatry Clin Neurosci. 2015;69(9):523-33. https://doi.org/10.1111/pen.12267.

22. Kasai $K$, Ando S, Kanehara A, Kumakura Y, Kondo S, Fukuda M, et al. Strengthening community mental health services in Japan. Lancet Psychiatry. 2017;4(4):268-70. https://doi.org/10.1016/S2215-0366(16)30373-X.

23. World Health Organization. mhGAP Intervention Guide Mental Health Gap Action Programme for mental, neurological and substance use disorders in non-specialized health settings. Geneva; 2016.

24. Church EA, Heath OJ, Curran VR, Bethune C, Callanan TS, Cornish PA. Rural professionals' perceptions of interprofessional continuing education in mental health. Health Soc Care Community. 2010;18(4):433-43. https://doi. org/10.1111/j.1365-2524.2010.00938.x.

25. Felsenstein J. Confidence limits on phylogenies: an approach using the bootstrap. Evol Int J Org Evol. 1985;39(4):783-91. https://doi.org/10.1111/j.1 558-5646.1985.tb00420.x.

26. Lumley T, Diehr P, Emerson S, Chen L. The importance of the normality assumption in large public health data sets. Annu Rev Public Health. 2002; 23(1):151-69. https://doi.org/10.1146/annurev.publhealth.23.100901.140546.

27. Cumming G. The new statistics: why and how. Psychol Sci. 2014;25(1):7-29. https://doi.org/10.1177/0956797613504966.
28. Carpenter J, Bithell J. Bootstrap confidence intervals: when, which, what? A practical quide for medical statisticians. Stat Med. 2000;19(9):1141-64. https://doi.org/10.1002/(SICI)1097-0258(20000515)19:9<1141::AID-SIM479>3. $0 . \mathrm{CO} ; 2-\mathrm{F}$.

29. World Health Organization. Mental Health Atlas. Geneva. 2014:2014.

30. Ito H, Koyama A, Higuchi T. Polypharmacy and excessive dosing: psychiatrists' perceptions of antipsychotic drug prescription. Br J Psychiatry J Ment Sci. 2005;187(3):243-7. https://doi.org/10.1192/bjp.187.3.243.

31. Oshima I, Mino Y, Inomata Y. Institutionalisation and schizophrenia in Japan: social environments and negative symptoms: Nationwide survey of inpatients. Br J Psychiatry J Ment Sci. 2003;183(1):50-6. https://doi.org/10.11 92/bjp.183.1.50.

32. Okayama T, Usuda K, Okazaki E, Yamanouchi Y. Number of long-term inpatients in Japanese psychiatric care beds: trend analysis from the patient survey and the 630 survey. BMC Psychiatry. 2020;20(1):522. https://doi.org/1 0.1186/s12888-020-02927-z.

33. Tachimori H, Takeshima T, Kono T, Akazawa M, Zhao X. Statistical aspects of psychiatric inpatient care in Japan: based on a comprehensive nationwide survey of psychiatric hospitals conducted from 1996 to 2012. Psychiatry Clin Neurosci. 2015;69(9):512-22. https://doi.org/10.1111/pcn.12297.

34. Ministry of Health, Labour and Welfare. Hospital Report. Tokyo; 2019.

35. Ministry of Health Labour and Welfare. New community mental health and its evaluation (Japanese). Tokyo; 2012.

\section{Publisher's Note}

Springer Nature remains neutral with regard to jurisdictional claims in published maps and institutional affiliations.
Ready to submit your research? Choose BMC and benefit from:

- fast, convenient online submission

- thorough peer review by experienced researchers in your field

- rapid publication on acceptance

- support for research data, including large and complex data types

- gold Open Access which fosters wider collaboration and increased citations

- maximum visibility for your research: over $100 \mathrm{M}$ website views per year

At BMC, research is always in progress.

Learn more biomedcentral.com/submissions 